\title{
BMJ Open Assessing the efficacy and impact of a personalised smoking cessation intervention among type 2 diabetic smokers: study protocol for an open- label randomised controlled trial (DISCGO-RCT)
}

Carole Clair (D) , ${ }^{1,2}$ Aurélie Augsburger (D) , ${ }^{1}$ Priska Birrer, ${ }^{1,2}$ Isabella Locatelli, ${ }^{1,2}$ Joelle Schwarz, ${ }^{1}$ Gilbert Greub, ${ }^{3}$ Anne Zanchi, ${ }^{4}$ Isabelle Jacot-Sadowski, ${ }^{5}$ Jardena J Puder ${ }^{6}$

To cite: Clair C, Augsburger A, Birrer $P$, et al. Assessing the efficacy and impact of a personalised smoking cessation intervention among type 2 diabetic smokers: study protocol for an open-label randomised controlled trial (DISCGO-RCT). BMJ Open 2020;10:e040117. doi:10.1136/ bmjopen-2020-040117

- Prepublication history and additional material for this paper are available online. To view these files, please visit the journal online (http://dx.doi. org/10.1136/bmjopen-2020040117).

Received 06 May 2020 Revised 12 October 2020 Accepted 21 October 2020

Check for updates

(C) Author(s) (or their employer(s)) 2020. Re-use permitted under CC BY-NC. No commercial re-use. See rights and permissions. Published by BMJ.

For numbered affiliations see end of article.

Correspondence to

Dr Carole Clair;

carole.clair@unisante.ch

\section{ABSTRACT}

Introduction Few studies have assessed the efficacy of smoking cessation interventions in individuals with type 2 diabetes, but interventions adapted to the specific needs of this population are warranted. The aim of this study is to assess the efficacy of a smoking cessation intervention in a population of smokers with type 2 diabetes and to measure the metabolic impact of smoking cessation. Methods and analysis The study is an open-label, randomised control trial. Participants recruited from a sanitary region of Switzerland will be randomly allocated to either the intervention or the control arm. The intervention group will have four individual counselling sessions over 12 weeks. Trained research nurses will conduct the behavioural intervention, using motivational interviews and addressing diabetes and gender specificities. The control group will have one short counselling session at baseline and will be given written information on smoking cessation. Both groups will have a follow-up visit at 26 and 52 weeks. Demographic and medical data will be collected at baseline and follow-up, along with blood and urine samples. The primary study outcome is continuous smoking abstinence validated by expired-air carbon monoxide from week 12 to week 52 . Secondary study outcomes are continuous and 7-day point prevalence smoking abstinence at 12 and 26 weeks; change in motivation to quit and cigarette consumption; and change in glycosylated haemoglobin levels, body weight, waist circumference and renal function after smoking cessation. In a subsample of 80 participants, change in stool microbiota from baseline will be measured at 3,8 and 26 weeks after smoking cessation.

Ethics and dissemination Ethical approval has been obtained by the competent ethics committee (Commission cantonale d'éthique de la recherche sur l'être humain, CER-VD 2017-00812). The results of the study will be disseminated through publications in peer-reviewed journals and conference presentations.

Trial registration numbers ClinicalTrials.gov NCT03426423 and SNCTP000002762; Pre-results.
Strengths and limitations of this study

- Smokers with various degrees of motivation to quit (including smokers not motivated to quit) are included with few exclusion criteria to ensure high external validity and thus clinical generalisability.

- The 12-month follow-up will assess the long-term efficacy of the behavioural smoking cessation intervention.

- The smoking cessation intervention is tailored to diabetes and gender specificities.

- The smoking cessation intervention is compared with usual care; thus, participants in the control group might benefit from other interventions that may contaminate the control group.

- As a result of group heterogeneity and few exclusion criteria, there is a higher risk of attrition.

\section{INTRODUCTION}

Smoking is the leading cause of avoidable death worldwide and among the top five causes of morbidity and decreased disabilityadjusted life-years. ${ }^{1}$ More than a quarter of the Swiss population currently smokes cigarettes. ${ }^{2}$ Similarly, diabetes is a major public health problem and its burden is increasing globally. ${ }^{3}$ In Switzerland, it is estimated that about 450000 people have diabetes, more than $90 \%$ of them having type 2. ${ }^{3}$ Smoking increases the risk of developing type 2 diabetes, and people with type 1 and type 2 diabetes who smoke are at increased risk of complications and premature death. ${ }^{4-6}$ Avoiding tobacco use could prevent a large proportion of cases of diabetes and its complications. ${ }^{7}$ 


\section{Smoking prevalence and impact on people with diabetes}

In those with diabetes, smoking has been repeatedly shown to increase the risk of mortality, ${ }^{8-12}$ as well as macrovascular complications such as coronary heart disease ${ }^{13-16}$ and stroke. ${ }^{17}$ Regarding microvascular complications, smoking has been shown to increase the risk of developing or worsening nephropathy, retinopathy ${ }^{18}$ and peripheral neuropathy. ${ }^{6}$

Despite the high rate of complications related to cigarette smoking, smoking prevalence remains high among people with diabetes. ${ }^{19-21}$

\section{Smoking cessation in people with diabetes}

It is a challenge for clinicians to induce a change in the behaviour of people with diabetes and to encourage a healthy lifestyle. ${ }^{22}$ Smokers with diabetes might differ from other smokers regarding not only their risks, but also their reasons for smoking and motivations to quit. Evidence suggests that they are less motivated to quit than other smokers, possibly because they fear weight gain. ${ }^{23} 24$ Smokers with diabetes are also more likely to have depression, ${ }^{2325}$ a condition that has been shown to hinder efforts to stop smoking. ${ }^{26}$ In addition, they may be inadequately informed about the benefits of smoking cessation or available options to help them quit. ${ }^{27} 28$ These factors explain in part why success rates for smoking cessation are often low among people with diabetes. ${ }^{29}$ Most smokers with diabetes are not aware of the important risk of microvascular and macrovascular complications associated with smoking $^{30}$ and often do not perceive smoking cessation as a top priority. ${ }^{31}{ }^{32}$ Rather, diabetic smokers are most concerned about their weight, dietary adherence and diabetes management. ${ }^{33}$ Moreover, health professionals might be less prone to give smoking cessation advice to people with diabetes. ${ }^{27}$

Limited evidence is available on the effectiveness and efficacy of smoking cessation interventions in people with diabetes. Several studies have tested multifactorial interventions (which included smoking cessation in addition to other interventions such as physical activity) with various levels of intensity. ${ }^{34-38}$ Some studies showed an increase in smoking abstinence in participants who received multifactorial intervention, ${ }^{36}$ but the effect of smoking was difficult to isolate or the studies lacked power to show significant results when restricted to smokers. ${ }^{35}$

A systematic review and meta-analysis, published in 2014, summarised randomised control trial studies that assessed smoking cessation interventions among people with diabetes. ${ }^{39}$ In this review, which included four studies, smoking cessation rates at 6 months were variable, ranging from $0 \%$ to $18 \%$, and the overall risk ratio of smoking cessation, which compared more intensive with less intensive smoking cessation interventions, was non-significant (risk ratio $1.32,95 \%$ CI 0.23 to 7.43 ) using a random-effects model.

The few studies that have prospectively assessed the impact of smoking cessation on diabetes control and complications show contradictory findings. In a case control study from Japan that included 31 participants with type 2 diabetes, smoking cessation was associated with an increase in body weight $(+1.2 \mathrm{~kg})$, glycosylated haemoglobin $(\mathrm{HbA1c})$ levels $(+1$ unit) and systolic and diastolic blood pressure at 12 months compared with continuing smoking. ${ }^{40}$ In contrast, in a 12 -month observational study that included 193 participants with newly diagnosed type 2 diabetes, smoking cessation was associated with improvement in microalbuminuria, insulin resistance, and glycaemic control and with a reduction in peripheral vascular disease and polyneuropathy, but it had no effect on retinopathy. ${ }^{41}$ Chaturvedi et al showed that former smokers with diabetes had a lower risk of mortality than did continuing smokers, risk attenuation increasing with length of cessation. ${ }^{42}$ In a study that included men only, smoking cessation was estimated to be the best way to prolong life in people with diabetes compared with other interventions for reducing cardiovascular risk factors. ${ }^{43}$ Thus, smoking cessation is highly beneficial for long-term outcomes among diabetic patients, but little is known about short-term outcomes such as weight gain and diabetes control following smoking cessation.

\section{Smoking, diabetes and microbiota}

Studies recently reported modifications of intestinal and oral/nasopharyngeal microbial flora after smoking cessation in non-diabetic human subjects. ${ }^{44-46}$ It has been hypothesised that a change in the microbiota among nondiabetic smokers (a change to 'obesogenic' flora) after smoking cessation might partly explain weight gain. ${ }^{45}$ Fingerprinting of the microbiota has been studied in people with diabetes and compared with that in cardiovascular and control groups. The diabetes group showed a significantly increased proportion of aerobic bacteria, an increased proportion of coliforms, and a reduced proportion of bifidobacteria; the balance between beneficial and pathogenic bacteria was disturbed among those with diabetes. ${ }^{47}$ Moreover, the increased proportion of coliforms (with highly active lipopolysaccharide) and aerobic bacteria might result in an increased rate of intraluminal inflammation and dysbiosis, possibly leading in some susceptible persons to irritable colon syndrome or inflammatory bowel disease. The design of the studies that assessed the change in microbiota after smoking cessation and the limited number of subjects makes it difficult to generalise the results. Furthermore, no studies have prospectively assessed the impact of smoking cessation on the gut microbiota of subjects with type 2 diabetes.

\section{Smoking, diabetes and gender}

The prevalence of type 2 diabetes seems to be higher among men than among women. ${ }^{48}$ Risk factors for diabetes and complications seem also to differ between men and women, as diabetes confers a higher cardiovascular disease risk among women. ${ }^{49-51}$ Concerning diabetes process of care, women have better glycaemic control and adherence to recommended self-care than men do. ${ }^{52}$ However, women with diabetes are less likely to receive 
aspirin or antihypertensive or lipid-lowering drugs, and are treated less aggressively, thus gaining poorer control over their cardiovascular disease risk factors than men can. ${ }^{53-55}$

Despite an overall decrease in smoking prevalence over the past decades in high-income countries ${ }^{56}$ the gap between men and women smokers has narrowed. ${ }^{57}$ Women have different reasons and motivations to smoke than men do. ${ }^{589}$ They are more likely to use cigarettes as a strategy to manage their weight and to cope with stress and emotions. ${ }^{58601}$ Furthermore, women have different concerns associated with quitting, such as weight gain. ${ }^{62} 63$ They have a higher perceived risk of quitting and are more likely to relapse because of weight gain. ${ }^{64} 65$ It is, thus, important to take into account gender and diabetes specificities to better address barriers to quitting and to improve success in smoking cessation.

\section{Smoking, diabetes, social stigma and depression}

Recent research has shown that patients with type 2 diabetes experience social stigma, as diabetes is portrayed as the 'blame and shame' disease associated with bad lifestyle habits (nutrition, sedentary behaviour, smoking). ${ }^{66-69}$ Sources of diabetes-related social stigma include the media, healthcare professionals, friends, family and colleagues. Social epidemiologists have provided evidence on the effect of social stigma on psychosocial stress, leading to hypertension and other poor health outcomes. ${ }^{70}$ They are pleading for further studies to include both individual-level and structural-level measures of stigma and their effect on health outcomes. It is hypothesised that diabetes social support groups and motivational interviews can play a role in reducing the structural stigma experienced by diabetic persons, and thus its psychosocial effect on health.

In addition, the bidirectional association between diabetes and depression is well established. ${ }^{72}$ In fact, while depression is often perceived as a consequence of diabetes due to the burden of chronic illness, research has shown that depression may be a risk factor for the development of diabetes, explained by the biochemical changes and poor health-related behaviour in persons with depression. ${ }^{72}$ It is here hypothesised that the motivational interview, which includes a depression component, has an effect on diabetes self-care management on the one hand, and allows screening and appropriate referral in case of depression on the other.

\section{Rationale for the study}

In the latest US guidelines for treating tobacco use and dependence, the authors conclude that additional research is needed on counselling, cessation medications, and the impact and effectiveness of tailored interventions in individuals with diabetes. ${ }^{73}$ The purpose of the current study is to evaluate the efficacy of a smoking cessation intervention tailored to diabetes and gender needs among type 2 diabetic smokers. The secondary purpose is to measure and compare the metabolic consequences

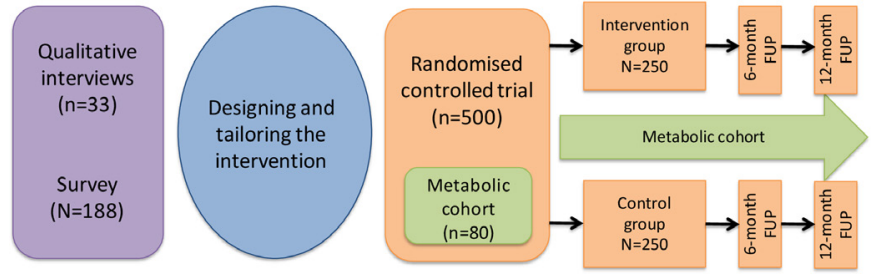

Figure 1 Diabetes and Smoking Cessation: a GenderOriented Study (DISCGO). Study 3 phase design figure. FUP, follow-up.

of smoking cessation and the influence of gut microbiota on metabolism among type 2 diabetics who successfully quit smoking and among those who continue to smoke. A substudy explores the relationship between social stigma, depression and diabetes self-care management.

\section{METHODS AND ANALYSIS \\ Design}

A total of 500 participants will be randomly assigned to either the intervention or the control group by using a computer-generated allocation method (orange area of figure 1). Allocation will be stratified by sex in order to obtain the same proportion of men and women in both groups.

\section{Intervention}

The intervention consists in behavioural smoking cessation. Combined pharmacotherapy and behavioural interventions have been shown to be effective in helping smokers to quit in the general population. ${ }^{73}{ }^{74}$ For the present study, we will use an evidence-based smoking cessation intervention and tailor it to the participants from the findings of the previous phases of our study. ${ }^{75}$

The smoking cessation intervention will be standardised and follow Swiss and international guidelines. ${ }^{7376} 77$ It will include both psychosocial support and evidenced-based pharmacotherapy treatment, which produce higher success rates when combined. ${ }^{74779}$ Counselling will cover topics such as assessing ambivalence and enhancing motivation with motivational interviewing methods ${ }^{80}$ (using, eg, past successes in the field of smoking cessation or other lifestyle changes such as diet or physical activity), identifying barriers to quit (that are specific to people with diabetes, such as weight and diabetes management), coping with cravings and intensive relapse prevention strategies. Participants will be advised to use over-thecounter nicotine replacement therapy (NRT). A 2-week starting kit will be provided, consisting of a nicotine transdermal patch, and a short-acting NRT will be provided to participants for free.

The behavioural intervention will last $30-45 \mathrm{~min}$ and will be conducted by research nurses. These study nurses will take basic training in motivational interviewing (certified training of 4 sessions of 4 hours each). They will have an interview guide that will be flexible enough to adapt 
to the patient's stage of motivation and preferences, as suggested by motivational interviewing techniques.

The intervention will follow the 5A steps, which is a well-described and systematic model currently being used in our smoking cessation outpatient clinic:

Ask for smoking status: The nurse will ask at each visit if the participant has smoked during the last 24 hours, the number of cigarettes (or other tobacco product) smoked, and the date of the last cigarette.

Assess motivations and need to quit: The nurse will assess the overall motivation to quit and the confidence to quit in the participants by using Likert scales from 1 to 10. She/he will also discuss with the participants their specific motivations to quit, as well as barriers and needs.

Advise about the possibility of smoking cessation and its benefits: The nurse will give information specific to diabetes that is adapted to the needs of the participants. This advice will be given by using recommended motivational interview techniques.

Assist the smoker to quit or decrease smoking by using a motivational interview \pm NRT: The nurse will then assist the participant to quit or change his/her cigarette consumption. No pressure will be put on smoking cessation, that is, no quit date will be fixed, unless the participant is ready and willing to quit, and every step towards a decrease in consumption will be encouraged. NRT will be systematically proposed to the participants in the intervention group who are willing to quit or decrease their consumption, but will be optional.

Arrange follow-up with the participant with 3 contacts of 30 min at weeks 3,8 and 12, in which the nurse will again address smoking cessation by using the 5As approach, motivational interviewing and cognitive-behavioural techniques.

\section{Control group}

Participants assigned to the control group will receive a less intensive and non-tailored intervention for smoking cessation. For this arm the structured three steps 'Ask, Advise, Refer' or 'AAR' approach will be used: Ask for smoking status. Advise to quit in a clear manner. Refer to external help: participants will receive a booklet with written information on smoking cessation (non-specific to diabetes and gender) and links to support facilities (national quitline, smoking cessation clinic, websites, self-help). This unique intervention of 5-10 min will be performed by the research nurse.

\section{Patient and public Involvement}

This study, DISCGO-RCT (Diabetes and Smoking Cessation: a Gender-Oriented Randomised Controlled Trial) is the next phase of the DISCGO-MIX study (CER-VD project ID: 302/15, Swissethics ID PB_2016-01459) (purple area of figure 1; see also below for details), which is intended to define the beliefs, motivations and specific needs of diabetic smokers by using a mixed-methods approach. ${ }^{75}$ Using qualitative methods, we explored patients with diabetes and healthcare provider's experiences and priorities. We adapted the intervention on the basis of their comments and preferences (eg, no interest in group sessions, desire for a motivational and 'guilt-free' approach). We did not discuss the design of the study with patients and did not include them in conducting the study. Nevertheless, we contacted patients' associations to help us recruit participants and diffuse information. We plan to send the participants the main results individually by using a simple factsheet with pictograms. We did not assess the burden of the intervention by the patients themselves before the start of the study.

\section{Sample size}

Power calculations indicate that a sample size of approximately 400 people is needed for the primary endpoint, that is, to detect a $10 \%$ difference in smoking abstinence between the intervention and control groups at 52 weeks with a 2-sample proportions test by using Pearson's $\chi^{2}$ test (power $80 \%$, significance level 0.05 ). From previous studies in the general population, smoking cessation rates are around 5\%-20\% without interventions. ${ }^{45}$ If we hypothesise that smoking abstinence in the control group will be $10 \%$ at 12 months, an increase of $10 \%$ in the intervention group, that is, a 12-month smoking abstinence of $20 \%$, would be considered clinically significant. We hypothesise a $20 \%$ attrition rate; therefore, the sample will be increased to 500 participants.

The analyses on the impact of smoking cessation on microbiota are exploratory and no sample size calculations have been performed. We will use a convenience sample of 80 participants (metabolic cohort).

\section{Outcomes}

The primary outcome is to assess the efficacy of a personalised smoking cessation behavioural intervention compared with usual care on validated continuous smoking abstinence among type 2 diabetic smokers for up to 52 weeks (see below and figure 2). The study calendar, including all visits, measures and questionnaire details, is shown in table 1 . Outcome measures are summarised in table 2 .

Smoking abstinence will be defined as a continuous abstinence rate from week 12 (end of intervention) to week 52 (end of follow-up), as recommended by the quality criteria for measuring smoking abstinence. ${ }^{81}$ Abstinence at each visit will be defined as a self-report of no smoking or use of other nicotine-containing products (electronic nicotine delivery system, smokeless tobacco) since the previous visit or contact, as confirmed by an expired carbon monoxide $(\mathrm{CO})$ level of $<10 \mathrm{ppm} .{ }^{81} 82$

The secondary outcomes for smoking cessation are as follows:

- Continuous smoking abstinence validated by $\mathrm{CO}$ at 12 and 26 weeks.

- 7-day point prevalence abstinence validated by $\mathrm{CO}$ at 12,26 and 52 weeks.

- Change in motivation to quit and number of quit attempts from baseline to 12, 26 and 52 weeks. 


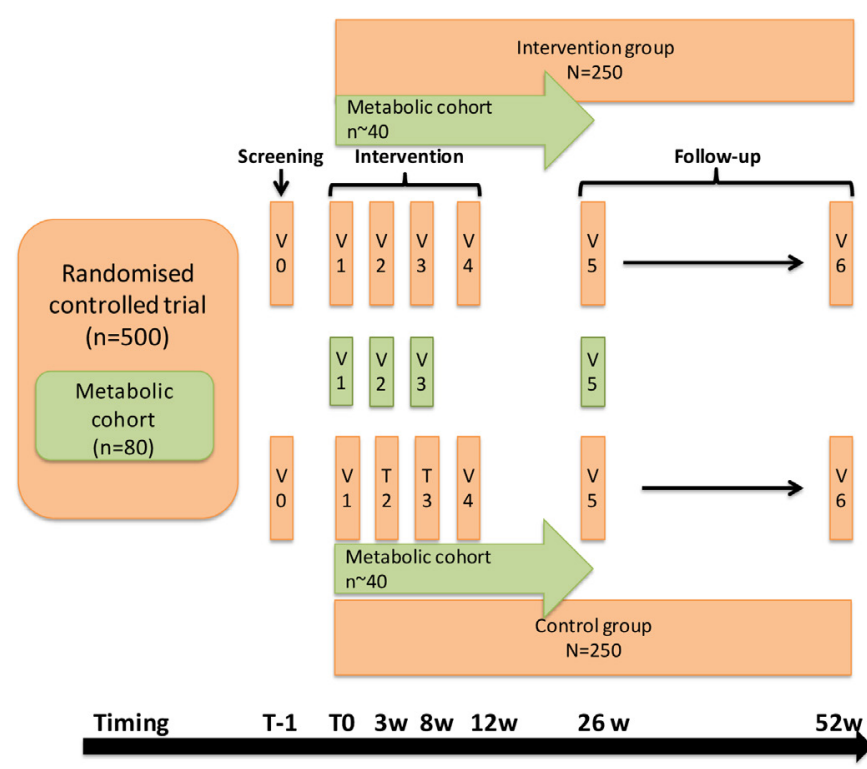

Figure 2 Randomised controlled study design with nested microbiota study figure. $\mathrm{V}$, visit.

- Harm reduction (decrease of $\geq 50 \%$ of cigarette consumption) at 12, 26 and 52 weeks.

The secondary metabolic endpoints are as follows:

- Change in body weight and waist circumference from baseline to 12, 26 and 52 weeks.

- Change in HbA1c levels from baseline to 12, 26 and 52 weeks.

- Change in renal function as assessed by the estimated glomerular filtration rate (eGFR) (Chronic Kidney Disease-Epidemiology Collaboration (CKD-EPI) creatinine-based formula) and albumin/creatinine ratio from baseline to 12,26 and 52 weeks.

The exploratory endpoint (metabolic cohort) is as follows:

- Change in faecal microbiota from baseline to 3,8 and 26 weeks. Different alpha and beta-diversity indexes will be used to characterise and compare the microbiota. Moreover, the rate of aerobic vs anaerobic bacteria, as well as the proportion of so-called beneficial gut bacteria such as species of Faecalibacterium and Akkermansia, will be compared between the different study groups.

The exploratory substudy on social stigma and depression will investigate the following:

- Association between social stigma (using the Everyday Discrimination Scale (EDS) $)^{83} 84$ and diabetes selfcare management (using the Summary of Diabetes Self-Care Activities (SDSCA) $)^{85}$ and between the EDS and HbA1c levels.

- Association between depression (using the Patient Health Questionnaire for Depression (PHQ-9) $)^{86}$ and diabetes self-care management (using the SDSCA) and between the PHQ-9 and HbA1c levels.

- Change in PHQ-9 score from baseline to 52 weeks.

\section{Study population}

Participants fulfilling all of the following inclusion criteria are eligible for the study:

- Informed consent as documented by signature.

- Having smoked >100 cigarettes during his/her entire life and currently smoking cigarettes (no minimal threshold).

- Having been diagnosed with type 2 diabetes.

- Being $\geq 18$ years old.

- Speaking and understanding French.

The presence of any one of the following exclusion criteria will lead to exclusion of the participant:

- Not being able to give informed consent and to follow the study procedure (due to dementia, psychological disorder, language problem).

- Being pregnant or breast feeding.

- Being enrolled in another smoking cessation study or programme or in a multibehavioural programme that includes smoking cessation.

- Enrolment of the investigator or other research collaborators, their family members, employees and other dependent persons.

- Planning to move out of Switzerland within the next year.

Inclusion and exclusion criteria for the renal secondary outcome:

- Same inclusion and exclusion criteria as above and,

- CKD with Kidney Disease Improving Global Outcomes CKD stage G3-5 (eGFR $<60 \mathrm{~mL} / \mathrm{min}$ based on the formula CKD-EPI (creatinine)) and/or stage A3 (urinary albumin/creatinine ratio $>30 \mathrm{mg} / \mathrm{mmol}$ on a urinary spot).

\section{Recruitment and screening}

Participants will be recruited from the Lausanne University outpatient clinics; medical or surgical wards (after discharge) of the Lausanne University Hospital; private practices of general internists and specialists in endocrinology from the region of Lausanne; the community via advertisements on selected websites, newspapers and social networks; pharmacies; and ambulatory centres from peripheral hospitals within a radius of $20-30 \mathrm{~km}$ around the investigation centre.

We will establish a list of all patients who have been admitted to the Lausanne University Hospital or outpatient clinic with a diagnosis of type 2 diabetes and a documented smoking status. Patients will be invited to participate to the study by letter. We will also post the information about study recruitment on the outpatient clinic website and on screens located in the waiting rooms. For participants recruited from pharmacies and private practices of generalists and/or specialists, flyers will be proactively distributed to potentially eligible patients by healthcare providers or local staff.

\section{Analysis plan}

Analyses for the primary outcome and secondary outcomes on smoking cessation will be done on an 


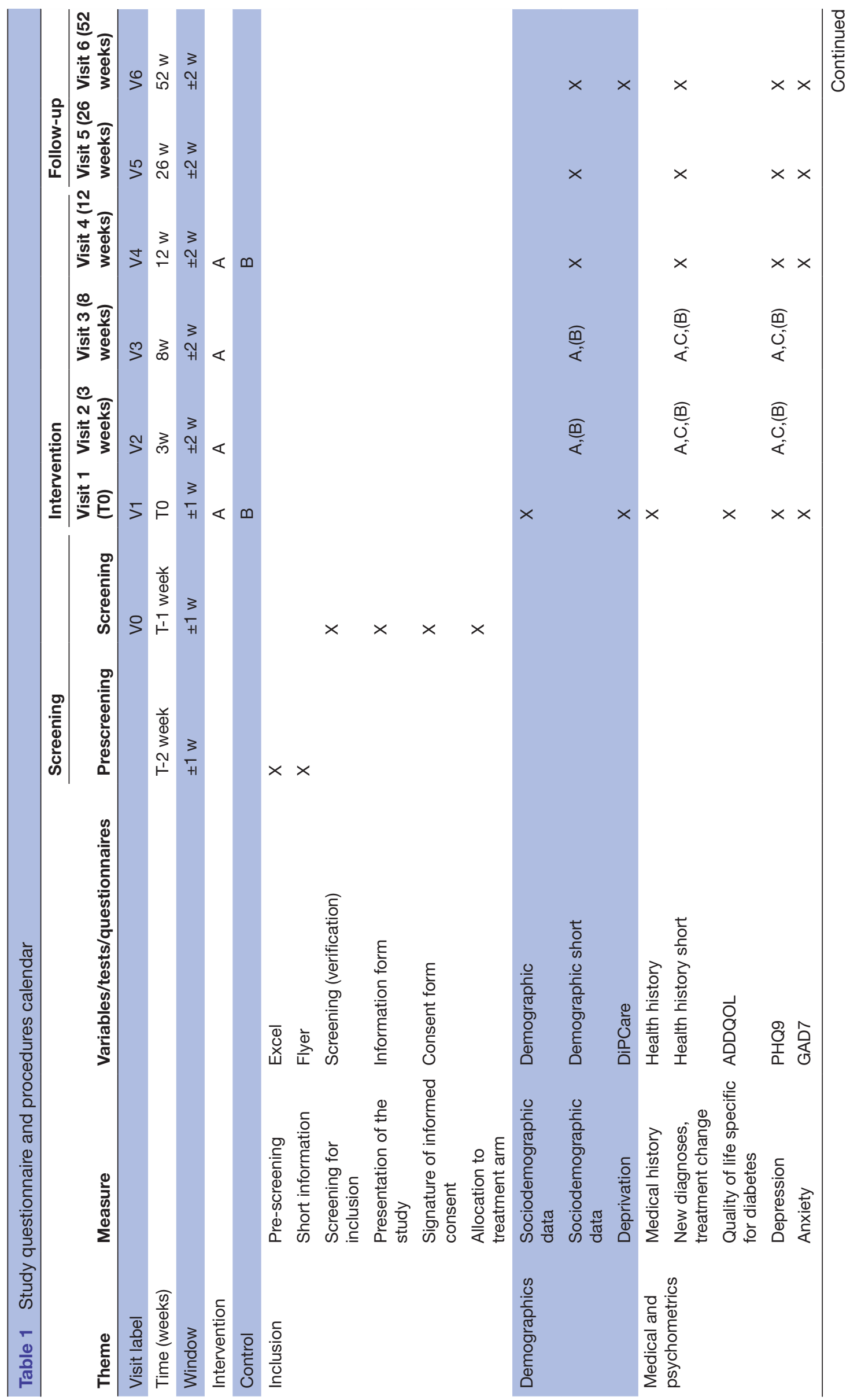

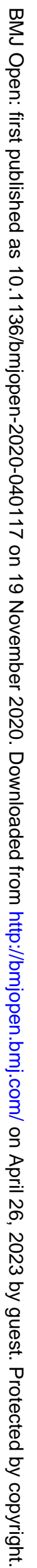




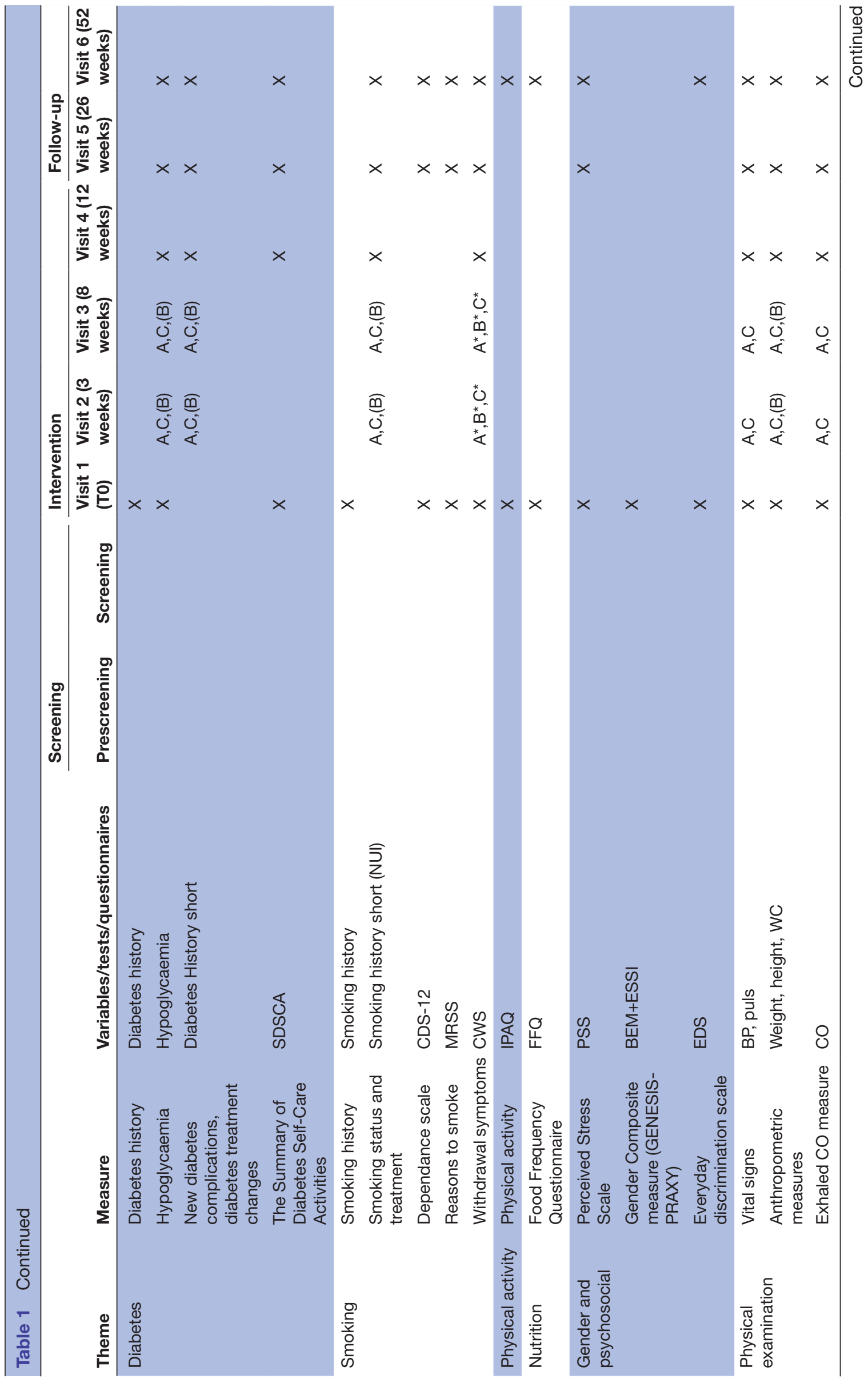




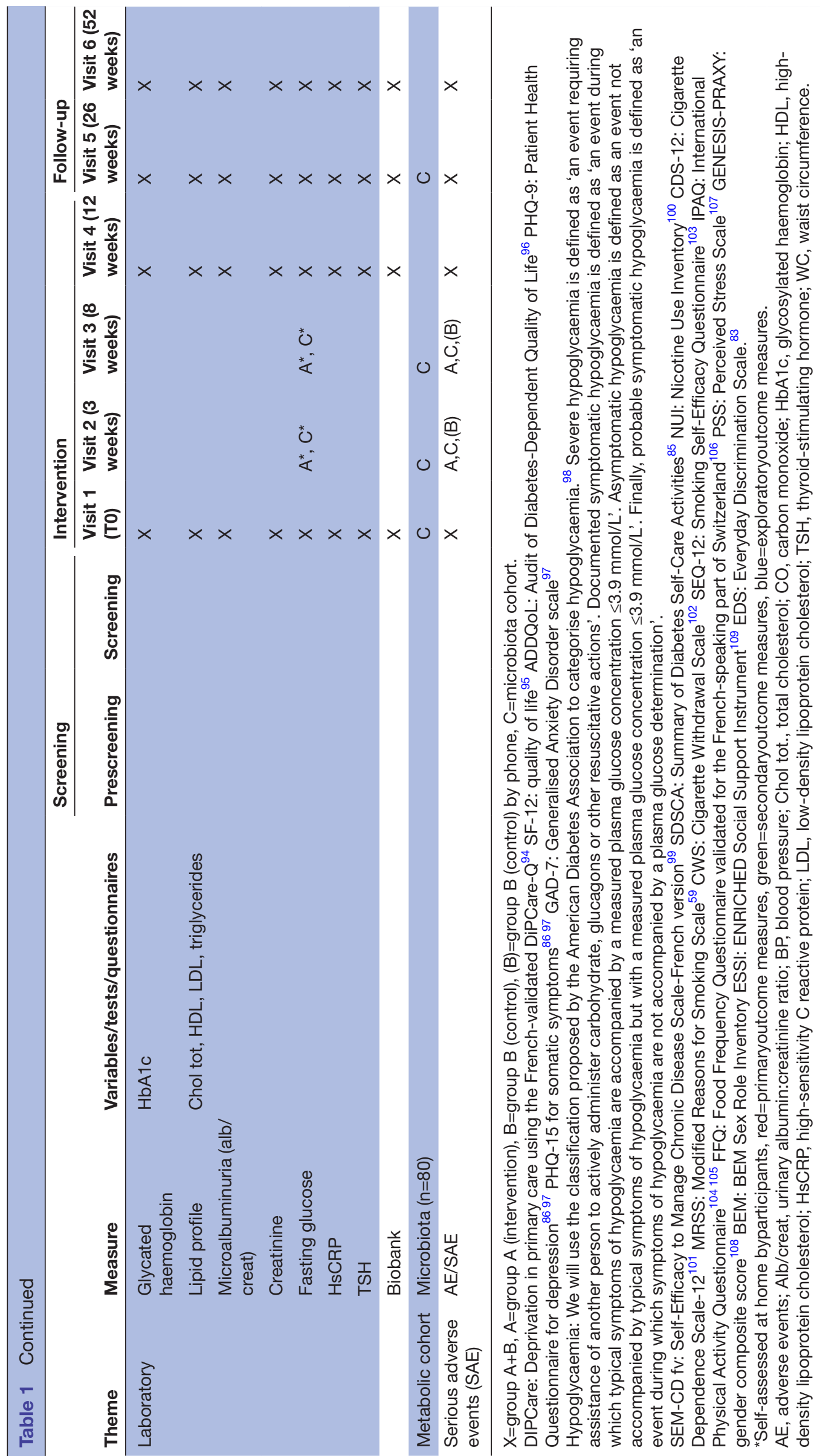




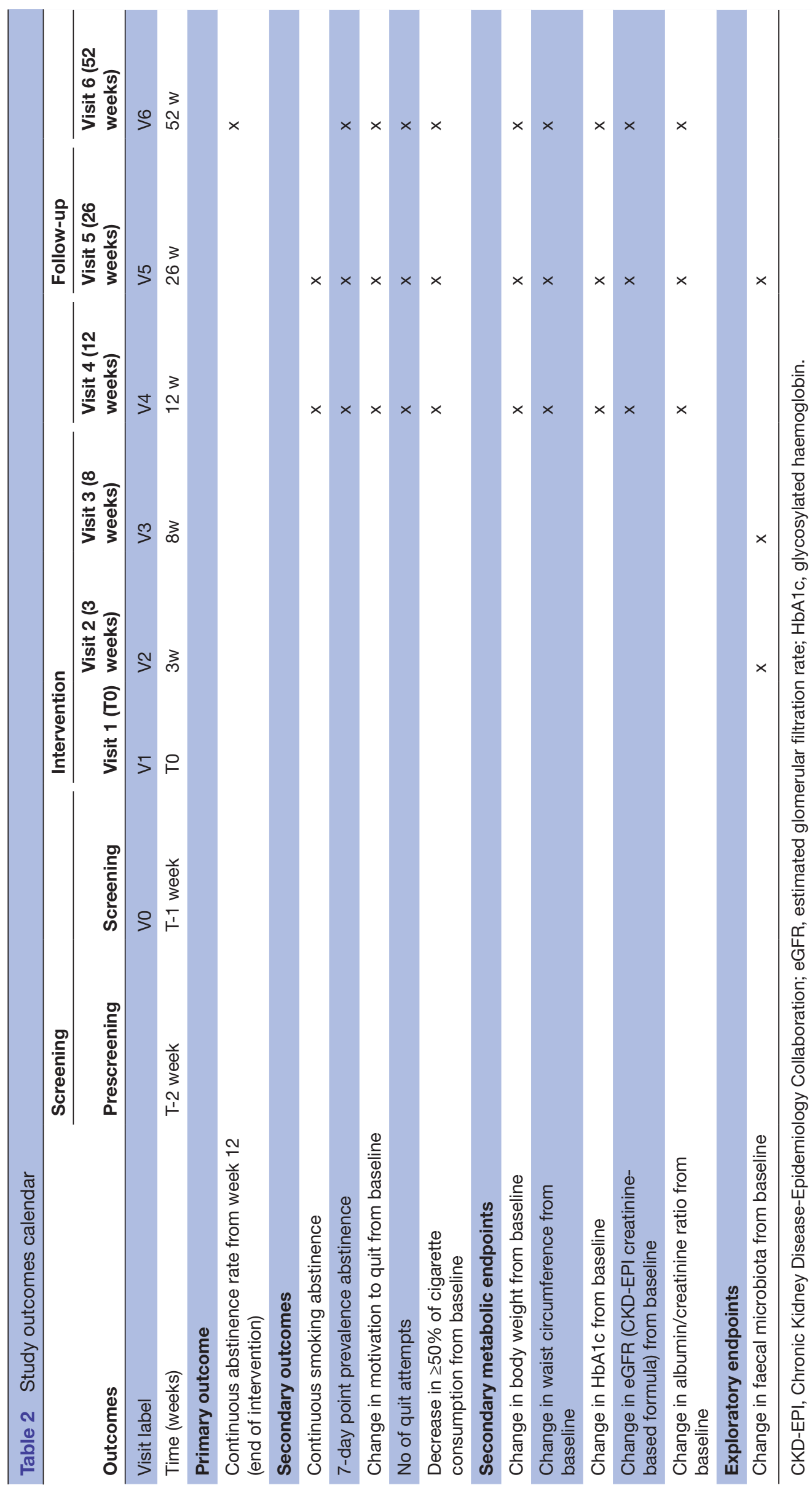

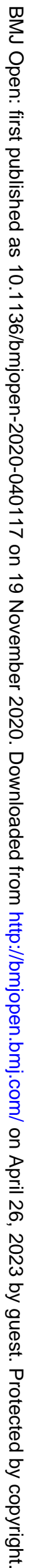


intention-to-treat basis. Participants lost to follow-up will be considered continuing smokers.

\section{Primary analyses}

Continuous smoking abstinence between weeks 12 and 52 will be compared between the intervention and the control group by using a Pearson $\chi^{2}$ test with a significance level of $p<0.05$. Analysis on the primary endpoint will be done by the research statistician, who will be blind to study groups. Similar analyses will be performed for other smoking cessation outcomes.

Stratified analyses for sex will be performed, with a $\chi^{2}$ test for analysing association between intervention and smoking cessation outcomes separately for each sex.

A logistic model for all smoking cessation (dichotomous) outcomes will be performed. The last (equivalent to the $\chi^{2}$ test in the unadjusted case) will allow us to:

1. Adjust for the type of smoking cessation treatment or help used by participant and not included into the study programme (participants will be free to use any smoking cessation treatment or help).

2. Test the effect of the interaction between intervention and sex on smoking abstinence for all outcomes, in order to explore if the intervention acts differently for the two sexes on the chances to stop smoking.

A longitudinal (generalised estimating equation) model will be used to compare abstinence trajectories between control and intervention groups, also adjusting for sex.

\section{Secondary analyses}

For metabolic outcome analyses on the nested metabolic cohort, the data will be used as a cohort and comparisons will be made between smokers who have managed to quit and continuing smokers.

A change in HbAlc levels from baseline will be compared between quitters and continuing smokers at 6 and 12 months by using t-tests with a significance level of $\mathrm{p}<0.05$ after verification of normality. Among quitters, we will perform supplementary analyses creating subgroups of quitters according to time since quitting (long-term vs short-term quitters).

The prevalence of diabetes control, defined as HbAlc levels of $<7 \%$, will be compared between quitters and continuing smokers at 6 and 12 months. Stratified and adjusted analyses for sex will be performed to assess whether there is a differential metabolic impact of smoking cessation between men and women (interaction sex/smoking cessation in a logistic model for diabetes control).

We will assess the potential role of mediating factors in the association between smoking cessation and glycaemic control (HbAlc continuous) or diabetes control (HbA1c levels of $<7 \%$ ) such as weight gain, waist circumference and high-sensitivity $\mathrm{C}$ reactive protein. To assess the potential role of these mediating factors, we will enter them in turn in a logistic or linear models and evaluate their potential influence on the estimate (potential mediating effect if we observe a $>10 \%$ change in the estimate).

Similar analyses will be performed for other laboratory variables (lipid profile, microalbuminuria, thyroidstimulating hormone).

Descriptive statistics will be performed to compare changes in faecal microbiota from baseline to 4, 8 and 26 weeks between quitters and continuing smokers. Analyses will be adjusted for the intervention group, baseline body mass index, change in weight, waist circumference, age, sex, change in diabetes therapy and other treatments, and use of nicotine. In addition to the classic phylumlevel analysis, we will also assess the impact of smoking cessation on diversity by using various indexes such as Shannon and on the presence or absence of various species-, genus- and family-level lineages. This analysis will first imply an assignment of the reads and then a subsequent description of the species, genus and family that are present in large amounts at baseline. A description of the variations of these specific species-level, genus-level and family-level lineages will then be assessed.

\section{Substudy analyses}

For the substudy, we will cross-sectionally (at w52) explore the association between social stigma (using EDS) and diabetes health outcomes (SDSCA and HbA1c levels), as well as between depression (PHQ-9) and the same health outcomes. To explore the hypothesis that social support may decrease social stigma, perceived stress and depression, and ultimately diabetes outcomes, we will further explore the path models between social support (diabetes support groups and/or motivational interview) and diabetes outcomes by using a structural equation modelling (SEM) approach $^{87}$ (hypothetical model as online supplemental material). We will develop a theory-driven SEM model (path diagram) using the constructs represented by latent factors (eg, social stigma, SDSCA) based on the literature and hypotheses. We will then, in an exploratory step, use study data for model respecification and fit testing, ensuring meaning of items and factors is maintained and theoretically explained.

\section{Data management}

Data will be collected by using electronic case record forms (Research Electronic Data Capture (REDCap) software) that will be securely stored for 10 years. Stata V.16.0 (StataCorp) and R (R Foundation for Statistical Computing, Vienna, Austria) will be used for statistical analyses.

\section{ETHICS AND DISSEMINATION}

Before the study started, the protocol, patient information and consent form, as well as other study-specific documents, were submitted to the appropriately constituted CEC (ie, Commission cantonale d'éthique de la recherche sur l'être humain du canton de Vaud, CERVD), in agreement with local legal requirements, for 
formal approval. Approval was obtained on 28 December 2017. The study started in March 2018 and is ongoing. Any amendment to the protocol will be sent to the CEC for approval.

The study will be carried out in accordance with the protocol and with the principles in the current version of the Declaration of Helsinki, ${ }^{88}$ the guidelines of Good Clinical Practice issued by the International Conference on Harmonization, ${ }^{89}{ }^{90}$ Swiss law ${ }^{91}$ and the requirements of the Swiss regulatory authority. ${ }^{92} 93$ The CEC will receive annual safety and interim reports and be informed about study stop/end in agreement with local requirements.

Risk-based monitoring will be performed by the Clinical Trial Unit, Lausanne (Switzerland).

The results of the study will be communicated and disseminated through conference presentations in national and international congresses of general internal medicine, endocrinology and tobacco research fields and through peer-reviewed manuscripts published in open-access journals. Depending on the results, we will propose implementing a smoking cessation intervention programme based on our model in diabetes clinics and in ambulatory care of our sanitary region (French part of Switzerland).

\section{Author affiliations}

${ }^{1}$ Department of Training, Research and Innovation, Center for Primary Care and Public Health, Lausanne, Vaud, Switzerland

${ }^{2}$ Faculty of Biology and Medicine, University of Lausanne, Lausanne, Switzerland ${ }^{3}$ Center for Research on Intracellular Bacteria, Institute of Microbiology, University Hospital of Lausanne, Lausanne, Switzerland

${ }^{4}$ Service of Nephrology and Hypertension, Service of Endocrinology, Diabetes and Metabolism, University Hospital of Lausanne Department of Medicine, Lausanne, Switzerland

${ }^{5}$ Department of Health Promotion and Prevention, Center for Primary Care and Public Health, Lausanne, Vaud, Switzerland

${ }^{6}$ Service of Obstetrics, Department Woman Mother Child, University Hospital of Lausanne, Lausanne, Vaud, Switzerland

Acknowledgements We thank the patients and healthcare providers for their help in the creation of this study and for providing us with their knowledge and valuable collaboration.Protocol version 5, 12.102019

Contributors Study concept and design: CC and JJP; Acquisition of data: AA, PB, JS; Draft of manuscript and statistical analysis: CC, AA, JS, PB, IL, AZ, GG, IJ-S and JJP; Revision of manuscript: All authors read and approved the manuscript for final publication. CC has the primary responsibility for the final content.

Funding This work was supported by a grant from the Swiss National Science Foundation (SNSF PZ00P3_154732) and a grant from the 'Fondation Pierre Mercier pour la Science', personally awarded to CC.

Competing interests None declared.

Patient consent for publication Not required.

Ethics approval Ethical approval has been obtained by the Competent Ethics Committee (CER-VD 2017-00812).

Provenance and peer review Not commissioned; externally peer reviewed.

Supplemental material This content has been supplied by the author(s). It has not been vetted by BMJ Publishing Group Limited (BMJ) and may not have been peer-reviewed. Any opinions or recommendations discussed are solely those of the author(s) and are not endorsed by BMJ. BMJ disclaims all liability and responsibility arising from any reliance placed on the content. Where the content includes any translated material, BMJ does not warrant the accuracy and reliability of the translations (including but not limited to local regulations, clinical guidelines, terminology, drug names and drug dosages), and is not responsible for any error and/or omissions arising from translation and adaptation or otherwise.

Open access This is an open access article distributed in accordance with the Creative Commons Attribution Non Commercial (CC BY-NC 4.0) license, which permits others to distribute, remix, adapt, build upon this work non-commercially, and license their derivative works on different terms, provided the original work is properly cited, appropriate credit is given, any changes made indicated, and the use is non-commercial. See: http://creativecommons.org/licenses/by-nc/4.0/.

ORCID iDs

Carole Clair http://orcid.org/0000-0001-5281-0943

Aurélie Augsburger http://orcid.org/0000-0002-8121-665X

\section{REFERENCES}

1 Murray CJL, Lopez AD. Measuring the global burden of disease. $N$ Engl J Med 2013;369:448-57.

2 Gmel G, Kuendig H, Notari L, et al. Monitorage suisse des addictions - Consommation d'alcool, tabac et drogues illégales en Suisse en 2012. Lausanne, Suisse, 2013.

3 IDF diabetes atlas, sixth edition. 2013, 2014. Available: http://www. idf.org/diabetesatlas

4 Willi C, Bodenmann P, Ghali WA, et al. Active smoking and the risk of type 2 diabetes: a systematic review and meta-analysis. JAMA 2007;298:2654-64.

5 Haire-Joshu D, Glasgow RE, Tibbs TL, et al. Smoking and diabetes. Diabetes Care 2004;27 Suppl 1:S74-5.

6 Clair C, Cohen MJ, Eichler F, et al. The effect of cigarette smoking on diabetic peripheral neuropathy: a systematic review and metaanalysis. J Gen Intern Med 2015;30:1193-203.

7 World Health Organisation. Who global report: mortality attributable to tobacco, 2012. Available: http://www.who.int/tobacco/ publications/surveillance/rep_mortality_attributable/en/

8 Moy CS, LaPorte RE, Dorman JS, et al. Insulin-Dependent diabetes mellitus mortality. the risk of cigarette smoking. Circulation 1990;82:37-43.

9 Manson JE, Rimm EB, Stampfer MJ, et al. Physical activity and incidence of non-insulin-dependent diabetes mellitus in women. Lancet 1991;338:774-8.

10 Stamler J, Vaccaro O, Neaton JD, et al. Diabetes, other risk factors, and 12-yr cardiovascular mortality for men screened in the multiple risk factor intervention trial. Diabetes Care 1993;16:434-44.

11 Uusitupa MI, Niskanen LK, Siitonen O, et al. Ten-Year cardiovascular mortality in relation to risk factors and abnormalities in lipoprotein composition in type 2 (non-insulin-dependent) diabetic and non-diabetic subjects. Diabetologia 1993;36:1175-84.

12 Klein R, Moss SE, Klein BE. Relation of ocular and systemic factors to survival in diabetes. Arch Intern Med 1989;149:266-72.

13 Al-Delaimy WK, Manson JE, Solomon CG, et al. Smoking and risk of coronary heart disease among women with type 2 diabetes mellitus. Arch Intern Med 2002;162:273-9.

14 Al-Delaimy WK, Willett WC, Manson JE, et al. Smoking and mortality among women with type 2 diabetes: the nurses' health study cohort. Diabetes Care 2001;24:2043-8.

15 Morrish NJ, Stevens LK, Fuller JH, et al. Risk factors for macrovascular disease in diabetes mellitus: the London follow-up to the who multinational study of vascular disease in diabetics. Diabetologia 1991;34:590-4.

16 Turner RC, Millns H, Neil HA, et al. Risk factors for coronary artery disease in non-insulin dependent diabetes mellitus: United Kingdom prospective diabetes study (UKPDS: 23). BMJ 1998;316:823-8.

17 Tuomilehto J, Rastenyte D, Jousilahti P, et al. Diabetes mellitus as a risk factor for death from stroke. prospective study of the middleaged Finnish population. Stroke 1996;27:210-5.

18 Eliasson B. Cigarette smoking and diabetes. Prog Cardiovasc Dis 2003:45:405-13.

19 Clair C, Meigs JB, Rigotti NA. Smoking behavior among US adults with diabetes or impaired fasting glucose. Am J Med 2013;126:541. e15-541.e18.

20 Le Boudec J, Marques-Vidal P, Cornuz J, et al. Smoking cessation and the incidence of pre-diabetes and type 2 diabetes: a cohort study. J Diabetes Complications 2016;30:43-8.

21 Corcillo A, Pivin E, Lalubin F, et al. Glycaemic, blood pressure and lipid goal attainment and chronic kidney disease stage of type 2 diabetic patients treated in primary care practices. Swiss Med Wkly 2017;147:w14459.

22 Kogan AJ. Overcoming obstacles to effective care of type 2 diabetes. Am J Manag Care 2009;15:S255-62. 
23 Solberg LI, Desai JR, O'Connor PJ, et al. Diabetic patients who smoke: are they different? Ann Fam Med 2004;2:26-32.

24 Ruggiero L, Rossi JS, Prochaska JO, et al. Smoking and diabetes: readiness for change and provider advice. Addict Behav 1999;24:573-8.

25 Haire-Joshu D, Heady S, Thomas L, et al. Depressive symptomatology and smoking among persons with diabetes. Res Nurs Health 1994;17:273-82.

26 Cinciripini PM, Wetter DW, Fouladi RT, et al. The effects of depressed mood on smoking cessation: mediation by postcessation self-efficacy. J Consult Clin Psychol 2003;71:292-301.

27 Malarcher AM, Ford ES, Nelson DE, et al. Trends in cigarette smoking and physicians' advice to quit smoking among people with diabetes in the U.S. Diabetes Care 1995;18:694-7.

28 Thresia CU, Thankappan KR, Nichter M. Smoking cessation and diabetes control in Kerala, India: an urgent need for health education. Health Educ Res 2009;24:839-45.

29 Scemama O, Hamo-Tchatchouang E, Le Faou AL, et al. Difficulties of smoking cessation in diabetic inpatients benefiting from a systematic consultation to help them to give up smoking. Diabetes Metab 2006;32:435-41.

30 Jenssen TG, Tonstad S, Claudi T, et al. The gap between guidelines and practice in the treatment of type 2 diabetes a nationwide survey in Norway. Diabetes Res Clin Pract 2008;80:314-20.

31 Glasgow RE, Hampson SE, Strycker LA, et al. Personal-mode beliefs and social-environmental barriers related to diabetes selfmanagement. Diabetes Care 1997;20:556-61.

32 Fowler PM, Hoskins PL, McGill M, et al. Anti-smoking programme for diabetic patients: the agony and the ecstasy. Diabet Med 1989;6:698-702

33 Wakefield M, Roberts L, Rosenfeld E. Prospects for smoking cessation among people with insulin-dependent diabetes. Patient Educ Couns 1998;34:257-66.

34 Gaede P, Beck M, Vedel P, et al. Limited impact of lifestyle education in patients with type 2 diabetes mellitus and microalbuminuria: results from a randomized intervention study. Diabet Med 2001;18:104-8.

35 Gæde P, Lund-Andersen $\mathrm{H}$, Parving $\mathrm{H}-\mathrm{H}$, et al. Effect of a multifactorial intervention on mortality in type 2 diabetes. $N$ Engl $J$ Med 2008;358:580-91.

36 Jones H, Edwards L, Vallis TM, et al. Changes in diabetes self-care behaviors make a difference in glycemic control: the diabetes stages of change (disc) study. Diabetes Care 2003;26:732-7.

37 Kirkman MS, Weinberger M, Landsman PB, et al. A TelephoneDelivered intervention for patients with NIDDM: effect on coronary risk factors. Diabetes Care 1994;17:840-6.

38 Hanefeld M, Fischer S, Schmechel H, et al. Diabetes intervention study: Multi-Intervention trial in newly diagnosed NIDDM. Diabetes Care 1991;14:308-17.

39 Nagrebetsky A, Brettell R, Roberts N, et al. Smoking cessation in adults with diabetes: a systematic review and meta-analysis of data from randomised controlled trials. BMJ Open 2014;4:e004107.

40 lino K, Iwase M, Tsutsu N, et al. Smoking cessation and glycaemic control in type 2 diabetic patients. Diabetes Obes Metab 2004;6:181-6.

41 Voulgari C, Katsilambros N, Tentolouris N. Smoking cessation predicts amelioration of microalbuminuria in newly diagnosed type 2 diabetes mellitus: a 1-year prospective study. Metabolism 2011;60:1456-64.

42 Chaturvedi N, Stevens L, Fuller JH, et al. Which features of smoking determine mortality risk in former cigarette smokers with diabetes? the world Health organization multinational Study Group. Diabetes Care 1997;20:1266-72.

43 Yudkin JS. How can we best prolong life? Benefits of coronary risk factor reduction in non-diabetic and diabetic subjects. $B M$ 1993;306:1313-8

44 Biedermann L, Brülisauer K, Zeitz J, et al. Smoking cessation alters intestinal microbiota: insights from quantitative investigations on human fecal samples using fish. Inflamm Bowel Dis 2014;20:1496-501.

45 Biedermann L, Zeitz J, Mwinyi J, et al. Smoking cessation induces profound changes in the composition of the intestinal microbiota in humans. PLoS One 2013;8:e59260.

46 Brook I, Gober AE. Effect of smoking cessation on the microbial flora. Arch Otolaryngol Head Neck Surg 2007;133:135-8.

47 Vamanu E, Pelinescu D, Sarbu I. Comparative fingerprinting of the human microbiota in diabetes and cardiovascular disease. J Med Food 2016;19:1188-95.
48 Sattar N. Gender aspects in type 2 diabetes mellitus and cardiometabolic risk. Best Pract Res Clin Endocrinol Metab 2013;27:501-7

49 Huxley R, Barzi F, Woodward M. Excess risk of fatal coronary heart disease associated with diabetes in men and women: meta-analysis of 37 prospective cohort studies. BMJ 2006;332:73-8.

50 Yusuf S, Hawken S, Ôunpuu S, et al. Effect of potentially modifiable risk factors associated with myocardial infarction in 52 countries (the INTERHEART study): case-control study. The Lancet 2004;364:937-52.

51 Rich-Edwards JW, Manson JE, Hennekens $\mathrm{CH}$, et al. The primary prevention of coronary heart disease in women. $N$ Engl J Med 1995;332:1758-66.

52 MK Y, Lyles CR, Bent-Shaw LA, et al. Sex disparities in diabetes process of care measures and self-care in high-risk patients. $J$ Diabetes Res 2013;2013:575814.

53 Ferrara A, Williamson DF, Karter AJ, et al. Sex differences in quality of health care related to ischemic heart disease prevention in patients with diabetes: the translating research into action for diabetes (triad) study, 2000-2001. Diabetes Care 2004;27:2974-6.

54 Ferrara A, Mangione CM, Kim C, et al. Sex disparities in control and treatment of modifiable cardiovascular disease risk factors among patients with diabetes: translating research into action for diabetes (triad) study. Diabetes Care 2008;31:69-74.

55 Wexler DJ, Grant RW, Meigs JB, et al. Sex disparities in treatment of cardiac risk factors in patients with type 2 diabetes. Diabetes Care 2005;28:514-20.

56 Marques-Vidal P, Cerveira J, Paccaud F, et al. Smoking trends in Switzerland, 1992-2007: a time for optimism? J Epidemiol Community Health 2011;65:281-6.

57 Fiore MC, Novotny TE, Pierce JP, et al. Trends in cigarette smoking in the United States. The changing influence of gender and race. JAMA 1989;261:49-55.

58 Women and smoking : a report of the Surgeon General 2001.

59 Berlin I, Singleton EG, Pedarriosse A-M, et al. The modified reasons for smoking scale: factorial structure, gender effects and relationship with nicotine dependence and smoking cessation in French smokers*. Addiction 2003;98:1575-83.

60 Fulkerson JA, French SA. Cigarette smoking for weight loss or control among adolescents: gender and racial/ethnic differences. $J$ Adolesc Health 2003;32:306-13.

61 Meyer KA, Kushi LH, Jacobs DR, et al. Dietary fat and incidence of type 2 diabetes in older lowa women. Diabetes Care 2001;24:1528-35.

62 Willi C, de Torrente de la Jara G, Closuit A. The specificities of women and tobacco: an overwiew. In: Tolson KP, Veksler EB, eds. Research Focus on Smoking and Women's Health. Nova Biomedical, 2008: 199-224.

63 Pirie PL, Murray DM, Luepker RV. Gender differences in cigarette smoking and quitting in a cohort of young adults. Am J Public Health 1991;81:324-7.

64 Robert C, Klesges LMK. Cigarette smoking as a dieting strategy in a university population. Int J Eat Disord 1988;7:413-9.

65 Toll BA, Salovey P, O'Malley SS, et al. Message framing for smoking cessation: the interaction of risk perceptions and gender. Nicotine Tob Res 2008;10:195-200.

66 Browne JL, Ventura A, Mosely K, et al. 'I call it the blame and shame disease': a qualitative study about perceptions of social stigma surrounding type 2 diabetes. BMJ Open 2013;3:e003384.

67 Potter L, Wallston K, Trief P, et al. Attributing discrimination to weight: associations with well-being, self-care, and disease status in patients with type 2 diabetes mellitus. J Behav Med 2015;38:863-75.

68 Kato A, Fujimaki Y, Fujimori S, et al. Psychological and behavioural patterns of stigma among patients with type 2 diabetes: a crosssectional study. BMJ Open 2017;7:e013425.

69 Gonzalez JS, Shreck E, Psaros C, et al. Distress and type 2 diabetes-treatment adherence: a mediating role for perceived control. Health Psychology 2015;34:505-13.

70 Krieger N, Sidney S. Racial discrimination and blood pressure: the cardia study of young black and white adults. Am J Public Health 1996;86:1370-8.

71 Krieger N. Discrimination and health inequities. Int $J$ Health Serv 2014:44:643-710.

72 Renn BN, Feliciano L, Segal DL. The bidirectional relationship of depression and diabetes: a systematic review. Clin Psychol Rev 2011;31:1239-46.

73 Fiore M, Jaén C, Baker T. Treating tobacco use and dependence: 2008 update. Rockville, MD: U.S. Department of Health and Human Services, Public Health Service, 2008. 
74 Stead LF, Lancaster T. Combined pharmacotherapy and behavioural interventions for smoking cessation. Cochrane Database Syst Rev 2012;10:CD008286.

75 Georges A, Galbiati L, Clair C. Smoking in men and women with type 2 diabetes: a qualitative gender-sensitive exploration of barriers to smoking cessation among people with type 2 diabetes. PLoS One 2019;14:e0221783.

76 Cornuz J, Jacot-Sadowski I, Humair JP, et al. Désaccoutumance Au tabac: Mise jour 2011 (1ère partie). Swiss Medical Forum 2011;11:156-9

77 Cornuz J, Jacot-Sadowski I, Humair JP, et al. Désaccoutumance au tabac: Mise jour 2011 (2e partie). Swiss Medical Forum 2011;11:172-6.

78 Stead LF, Buitrago D, Preciado N, et al. Physician advice for smoking cessation. Cochrane Database Syst Rev 2013;5:CD000165

79 Stead LF, Perera R, Bullen C, et al. Nicotine replacement therapy for smoking cessation. Cochrane Database Syst Rev 2012;11:CD000146.

80 Lai DT, Cahill K, Qin Y, et al. Motivational interviewing for smoking cessation. Cochrane Database Syst Rev 2010:CD006936.

81 West R, Hajek P, Stead L, et al. Outcome criteria in smoking cessation trials: proposal for a common standard. Addiction 2005;100:299-303.

82 Hughes JR, Keely JP, Niaura RS, et al. Measures of abstinence in clinical trials: issues and recommendations. Nicotine Tob Res 2003;5:13-26.

83 Williams DR, Yan Yu, Jackson JS, et al. Racial differences in physical and mental health: socio-economic status, stress and discrimination. J Health Psychol 1997;2:335-51.

84 Williams DR. Measuring discrimination resource. Psychology 1997;2:335-51.

85 Toobert DJ, Hampson SE, Glasgow RE. The summary of diabetes self-care activities measure: results from 7 studies and a revised scale. Diabetes Care 2000;23:943-50.

86 Kroenke K, Spitzer RL, Williams JB. The PHQ-9: validity of a brief depression severity measure. J Gen Intern Med 2001;16:606-13.

87 Hox JJ, Bechger TM. An introduction to structural equation modeling. Fam Sci Rev 1998;11:354-73.

88 Declaration of Helsinki, version October, 2013. Available: http:// www.wma.net/en/30publications/10policies/b3/index.html

89 International Conference on harmonization $(\mathrm{ICH}, 1996) \mathrm{E} 6$ guideline for good clinical practice. Available: http://www.ich.org/fileadmin/ Public_Web_Site/ICH_Products/Guidelines/Efficacy/E6_R1/Step4/ E6_R1 Guideline.pdf

90 International Conference on harmonization (ICH, 1997) E8 guideline: general considerations for clinical trials. Available: http://www.ich org/fileadmin/Public_Web_Site/ICH_Products/Guidelines/Efficacy/ E8/Step4/E8_Guideline.pdf

91 Humanforschungsgesetz, HFG Bundesgesetz über die Forschung am Menschen (Bundesgesetz über die Forschung am Menschen, HFG) vom 30. September 2011/ Loi fédérale relative la recherche sur l'être humain (loi relative la recherche sur l'être humain, LRH) du 30 septembre 2011. Available: http://www.bag.admin.ch/themen/ medizin/00701/00702/07558/index.html?lang=fr

92 Verordnung über klinische Versuche in der Humanforschung (Verordnung über klinische Versuche, KlinV) vom 20. September
2013 / Ordonnance sur les essais cliniques dans le cadre de la recherche sur l'être humain (Ordonnance sur les essais cliniques, OClin) du 20 septembre, 2013. Available: http://www.bag.admin.ch/ themen/medizin/00701/00702/12310/index.html?lang=fr

93 Heilmittelgesetz HMG Bundesgesetz über Arzneimittel und Medizinprodukte (Heilmittelgesetz, HMG) vom 15. Dezember 2000/ Loi fédérale sur les médicaments et les dispositifs médicaux (Loi sur les produits thérapeutiques, Lpt) Du 15 décembre, 2000. Available: http://www.admin.ch/ch/d/sr/8/812.21.de.pdf

94 Vaucher P, Bischoff T, Diserens E-A, et al. Detecting and measuring deprivation in primary care: development, reliability and validity of a self-reported questionnaire: the DiPCare-Q. BMJ Open 2012;2:e000692.

95 Maruish MEE. User's manual for the SF-12v2 Health Survey. 3rd ed 2012.

96 Fung CSC, Wan EYF, Yu CLY, et al. Validity and reliability of the 19-item audit of Diabetes-Dependent quality of life (ADDQoL-19) questionnaire in Chinese patients with type 2 diabetes mellitus in primary care. Qual Life Res 2016;25:2373-8.

97 Kroenke K, Spitzer RL, Williams JBW, et al. The patient health questionnaire somatic, anxiety, and depressive symptom scales: a systematic review. Gen Hosp Psychiatry 2010;32:345-59.

98 Workgroup on Hypoglycemia, American Diabetes Association. Defining and reporting hypoglycemia in diabetes: a report from the American diabetes association Workgroup on hypoglycemia. Diabetes Care 2005;28:1245-9.

99 Hudon Cet al. The self-efficacy for managing chronic disease scale - French version: a validation study in primary care. Eur J Pers Cent Healthc 2014;2:533-8.

100 Koegelenberg CFN, Noor F, Bateman ED, et al. Efficacy of varenicline combined with nicotine replacement therapy vs varenicline alone for smoking cessation: a randomized clinical trial. JAMA 2014;312:155-61.

101 Etter J-F, Le Houezec J, Perneger TV. A self-administered questionnaire to measure dependence on cigarettes: the cigarette dependence scale. Neuropsychopharmacology 2003;28:359-70.

102 Etter J-F, Hughes JR. A comparison of the psychometric properties of three cigarette withdrawal scales. Addiction 2006;101:362-72.

103 Etter J-F, Bergman MM, Humair J-P, et al. Development and validation of a scale measuring self-efficacy of current and former smokers. Addiction 2000;95:901-13.

104 IPAQ. Available: www.ipaq.ki.se

105 Mäder U, Martin BW, Schutz Y, et al. Validity of four short physical activity questionnaires in middle-aged persons. Med Sci Sports Exerc 2006;38:1255-66.

106 Bernstein M, Morabia A, Costanza MC, et al. [Nutritional balance of the diet of the adult residents of Geneva]. Soz Praventivmed 1994;39:333-44.

107 Cohen S, Kamarck T, Mermelstein R. A global measure of perceived stress. J Health Soc Behav 1983;24:385-96.

108 Pelletier R, Ditto B, Pilote L. A composite measure of gender and its association with risk factors in patients with premature acute coronary syndrome. Psychosom Med 2015;77:517-26.

109 Vaglio J, Conard M, Poston WS, et al. Testing the performance of the ENRICHD social support instrument in cardiac patients. Health Qual Life Outcomes 2004;2:24 